\title{
CONSTRUÇÃO E AVALIAÇÃO DE UM MUSEU VIRTUAL DOS RESÍDUOS SÓLIDOS
}

\author{
Nilva Lúcia Rech Stedile ${ }^{1}$ \\ Rui Rafael Faraco Giacomoni²
}

Resumo: As tecnologias da informação permitiram a humanidade construir museus na dimensão virtual. $O$ presente artigo relata a experiência da construção de um site para abrigar o Museu Virtual Resíduos Sólido (MVRS) na área das Engenharias e Ciências Ambientais. A construção do site do MVRS foi dividida em duas fases, (Revisão bibliográfica, Processo de construção do Museu), sendo a segunda dividida em cinco etapas (Elaboração de um fluxograma, Definição da organização do Museu e dos conceitos que o compõem, Processo de elaboração do site MVRS, Avaliação do MVRS e Socialização do MVRS). A avaliação do MVRS, mostrou que a construção do site do MVRS foi bem aceita pelo público. Destaca-se a necessidade de monitoramento e avaliação constante do Museu, como forma de garantir sua eficácia.

Palavras-chave: Resíduos Sólidos; Museu Virtual; Construção. 


\section{Introdução}

Para entendimento da expressão Museu Virtual dos Resíduos Sólidos (MVRS) é necessário definir quatro conceitos básicos: museu; museu virtual; resíduos sólidos; Educação Ambiental. Um museu pode ser considerado, na contemporaneidade, segundo o Estatuto de Museus instituído pela Lei oㅡ 11.904 (BRASIL, 2009), como espaços que conservam, investigam, interpretam e comunicam as/sobre coleções e informações associadas, tencionando o usufruto público e a geração de sentidos. Ainda de um prisma legal, os museus são definidos pelo Conselho Internacional de Museus (ICOM) como:

uma instituição permanente, sem fins lucrativos, ao serviço da comunidade e do seu desenvolvimento, aberto ao público, e que adquire, conserva, estuda, comunica e expõe testemunhos materiais do homem e do seu meio ambiente, tendo em vista o estudo, educação e fruição (ICOM, 2004, sp).

Segundo Lévy (1999, p.15), a palavra virtual:

Vem do latim virtualis, derivado por sua vez de virtus, força, potência. Na filosofia escolástica, é virtual o que existe em potência e não em ato. [...] Em termos rigorosamente filosóficos, o virtual não se opõe ao real, mas ao atual: virtualidade e atualidade são apenas duas maneiras de ser diferentes. Significa que, com o advento das TICs é possível ultrapassar a esfera do Museu Real e implementa-los de forma virtual.

Segundo Souza (2008, p.107), as novas tecnologias de informação e de comunicação (NTICs) desempenham papel crucial no estabelecimento de novas sociabilidades e de novas ambiências educativas. Entre essas pode ser destacada a emergência das redes de informação e conhecimento, alicerçadas de vários modos, desde listas de correio eletrônico (mail lists) e bate-papos eletrônicos (chats) até comunidades virtuais (cybercomunities).

Conforme Menezes et al. (2012), na era da informática, várias ciências se apropriaram dos benefícios do uso de seus produtos, como computadores e multimídias, inclusive a educação. São diversos os programas lançados no mercado nacional e internacional anualmente e as geotecnologias surgiram trazendo algumas contribuições ao ensino. Significa que as tecnologias educacionais, por meio do uso da internet, cada vez mais fazem parte dos processos de ensinar e aprender em todos os níveis de ensino, formal ou não formal. 
Um aspecto fundamental em termos de aprendizagem diz respeito a imediata necessidade de a humanidade diminuir a geração de resíduos e maneja-los adequadamente, para reduzir os riscos à sobrevivência do planeta.

A NBR 10.004, da Associação Brasileira de Normas Técnicas (ABNT, 2004), define resíduos sólidos e semissólidos como aqueles "resultantes de atividades de origem industrial, doméstica, hospitalar, comercial, agrícola, de serviços e de varrição". A Norma inclui ainda nessa definição, os lodos provenientes dos sistemas de tratamento de água, aqueles gerados em equipamentos e instalações de controle de poluição, bem como determinados líquidos cujas particularidades tornem inviável o seu lançamento na rede pública de esgotos, em corpos de água, ou exijam para isso soluções técnicas e economicamente inviáveis em face à melhor tecnologia disponível.

A Lei № 12.305, de 2 de Agosto de 2010 que institui a Política Nacional de Resíduos Sólidos (BRASIL, 2010), em seu Art. 1ํㅡ, dispõe sobre seus princípios, objetivos e instrumentos, bem como sobre as diretrizes relativas à gestão integrada e ao gerenciamento de resíduos sólidos, incluídos os perigosos, às responsabilidades dos geradores e do poder público e aos instrumentos econômicos aplicáveis. No Capítulo II, para os efeitos desta Lei, conceitua resíduos sólidos no art. 3ํ, XVI, como sendo:

Todo material, substância, objeto ou bem descartado resultante de atividades humanas em sociedade, a cuja destinação final se procede, se propõe proceder ou se está obrigado a proceder, nos estados sólido ou semissólido, bem como gases contidos em recipientes e líquidos cujas particularidades tornem inviável o seu lançamento na rede pública de esgotos ou em corpos d'água, ou exijam para isso soluções técnica ou economicamente inviáveis em face da melhor tecnologia disponível (BRASIL, 2010).

Considerando que a geração de resíduos aumenta constantemente e seus efeitos são cumulativos, um MVRS pode contribuir e facilitar o acesso à informação, bem como tornar visível a problemática dos resíduos em todas as dimensões que o compõem. Pode ainda contribuir com a Educação Ambiental (EA), uma vez que reúne informação de qualidade e necessária a construção de conhecimentos sobre esse tema que é de responsabilidade da sociedade como um todo.

A Educação Ambiental tornou-se lei em 1999. A Lei № 9.795 (Lei da Educação Ambiental), em seu Art. $2^{\circ}$ afirma: "A Educação Ambiental é um componente essencial e permanente da educação nacional, devendo estar presente, de forma articulada, em todos os níveis e modalidades do processo educativo, em caráter formal e não-formal" (BRASIL, 1999). Segundo a mesma Lei, a EA formal acontece na educação escolar, privada ou pública, nos vários níveis e modalidades. A Educação não-formal corresponde as ações e práticas 
educativas voltadas à sensibilização da coletividade, fora dos ambientes educacionais formais.

As Diretrizes Curriculares Nacionais (DCN) para a EA objetivam, entre outros, a construção da responsabilidade cidadã, na reciprocidade das relações dos seres humanos entre si e com a natureza (BRASIL, 2012) e precisa, para ser eficaz, atingir capilaridade, ou seja, os atores envolvidos em processos de EA devem imprimir ao desenvolvimento individual um caráter social em sua relação com o meio ambiente, transformando-se em agentes ambientais, visando potencializar a prática de promover ética e cidadania ambiental (BRASIL, 1999; BRASIL, 2012).

Pelicioni (2015) ressalta a necessidade da EA ser desenvolvidas de forma interdisciplinar e alerta que a abordagem curricular nas áreas de conhecimento aparece ainda de forma compartimentada, o que dificulta 0 aprofundamento do pensamento crítico-reflexivo dos estudantes de forma integral e transversal acerca importância da socialização de conhecimentos que visem a preservação do ambiente em que vivemos.

$O$ presente artigo tem a finalidade de descrever os passos que foram feitos para a elaboração do MVRS com vistas a facilitar o processo de elaboração de museus virtuais que podem tornar acessível às pessoas assuntos relevantes à proteção ambiental. Pode colaborar também para redução das ameaças que as ações antrópicas têm imputado cotidianamente ao planeta.

\section{Metodologia}

Para proposição do MVRS foram realizadas duas fases, sendo a segunda dividida em 5 etapas.

\section{Fase 1: Pesquisa documental}

Desenvolvida buscando definir os termos: museu; museu virtual e resíduos sólidos. Esta revisão bibliográfica consistiu-se em leis, normas, decretos, resoluções, políticas públicas, fotos, ilustrações, materiais visuais e definições sobre os assuntos a serem abordados.

\section{Fase 2: Processo de construção do MVRS}

2.1 Elaboração de um fluxograma, que buscou verificar os itens a serem abordados na elaboração do Museu e norteou seu processo de criação. Fluxogramas são formas de representar, por meio de símbolos gráficos, a sequência dos passos de um trabalho para facilitar sua análise. Um fluxograma é um recurso visual frequentemente utilizado por gerentes de produção para analisar sistemas produtivos, buscando identificar oportunidades para melhorar a eficiência dos processos (PEINADO; GRAEML, 2007, p. 539). 
$\mathrm{Na}$ Figura a seguir é apresentado o fluxograma orientador da construção do site do MVRS.

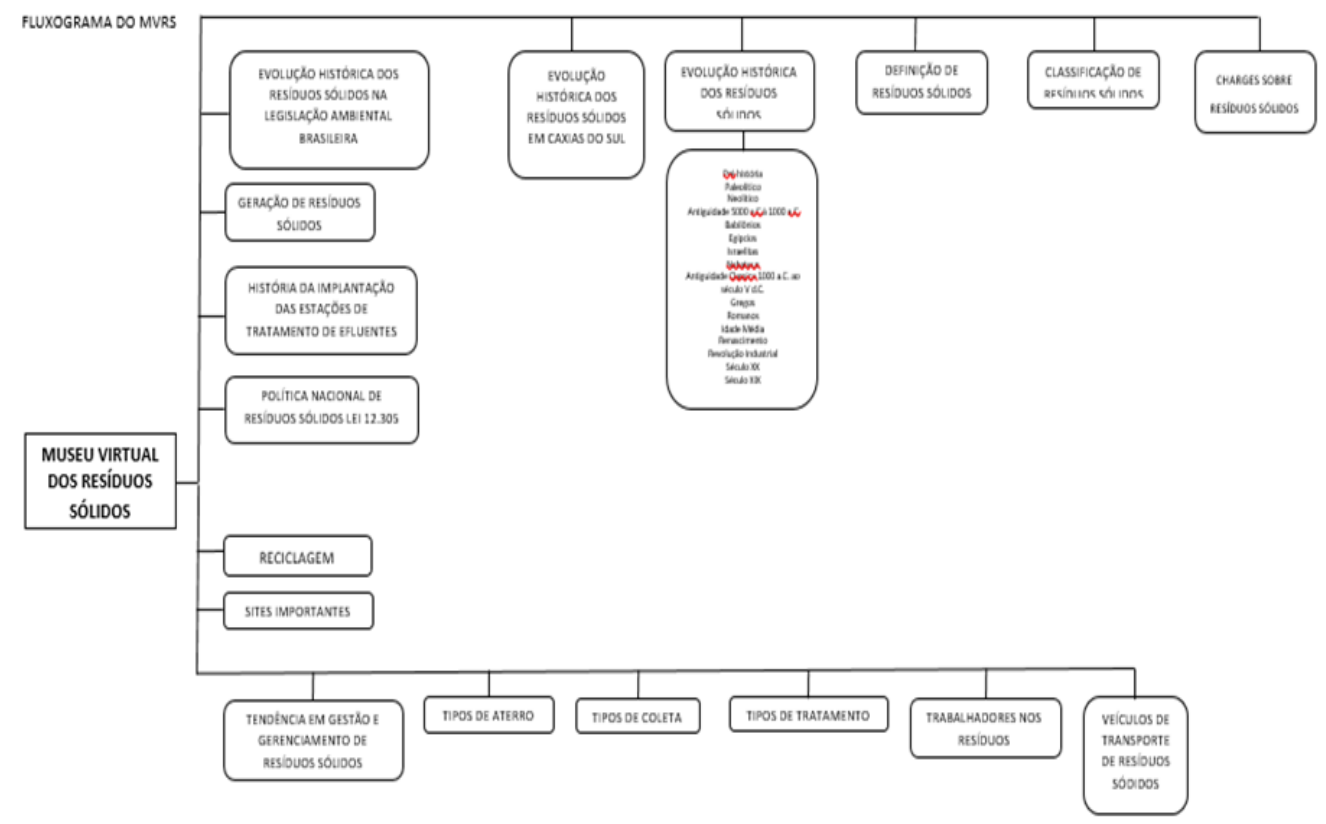

Figura 1: Fluxograma do site MVRS.

Fonte: elaborado pelo autor. compõem

2.2 Definição da organização do Museu e dos conceitos que o

O fluxograma do Museu Virtual do Resíduos Sólidos (MVRS), tem uma ramificação comum que são os Resíduos Sólidos. Após colocar os Resíduos Sólidos é interligado a ele os principais tópicos que são abordados no site do MVRS. Cada um dos tópicos foi definido em resposta a pergunta: O que é este tópico?, originando assim uma definição e, consequentemente, um exemplo.

\subsection{Processo de elaboração do site MVRS}

Nesta etapa buscou-se as possibilidades técnicas para a construção do site que abrigou o MVRS, por meio do Google site. O MVRS foi feito no novo Google site clássico.

O Museu Virtual de Resíduos Sólidos foi pensado para ser um local na web de interatividade e interação, para ser usufruído pelo público que se interesse por educação e memória e que tenha interesse nesta área. Assim, o design do Museu se configurou a partir de duas máximas: acessibilidade e navegabilidade. Ou seja, as configurações técnicas permitem que o Museu seja acessado de qualquer computador ou aparelho eletroeletrônico que receba um sinal de internet. 


\subsection{Avaliação do Museu Virtual dos Resíduos Sólidos}

Para testar a funcionalidade e a qualidade das informações foi realizada uma avaliação do Museu com alunos e professores dos mestrados da UCS, totalizando 26 avaliadores.

Foram critérios de inclusão dos avaliadores: estar cursando o Mestrado em Engenharia e Ciências Ambientais; Mestrado em Direito Ambiental; Mestrado de Filosofia e Educação; e Mestrado em Administração, por serem áreas que possuem interface com a proposta desse Museu. As variáveis avaliadas foram: primeira impressão sobre o site; frequência de utilização da internet; facilidade em navegar no site; abrangência do conteúdo sobre resíduos sólidos; qualidade das informações; como percebem a ideia da criação de um Museu Virtual; importância das informações disponibilizadas; possibilidade do uso da informação; impacto dos resíduos sólidos no meio ambiente. Além do levantamento da percepção dos participantes sobre essas variáveis foram solicitadas sugestões dos respondentes para o aprimoramento do MVRS.

2.5 Socialização do Museu Virtual dos Resíduos Sólidos

Esta última etapa consiste na socialização do MVRS para o público em geral.

\section{Resultados e Discussão}

Os resultados estão apresentados em dois subitens, relacionados ao processo de construção do Museu e sua avaliação.

\section{Processo de construção do MVRS} Figura 2.

Ao acessar o MVRS, o internauta encontrará a tela apresentada na

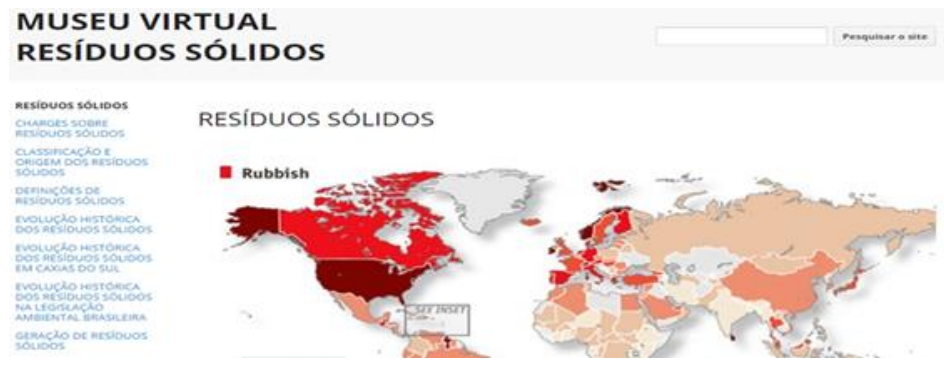

Figura 2: Representação do layout do site do Museu Virtual dos Resíduos Sólidos (MVRS). Fonte: elaborado pelo autor.

A partir da tela inicial, a navegabilidade se dará por meio da barra à esquerda, conforme Figura 3. 


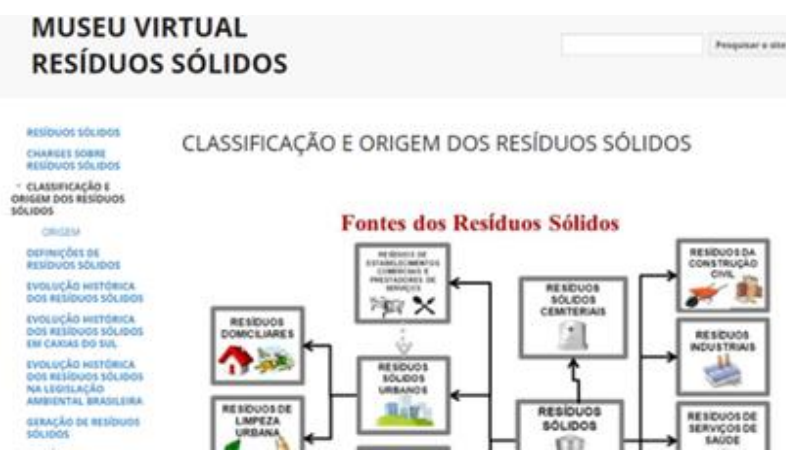

Figura 3: Navegabilidade do MVRS.

Fonte: elaborado pelo autor.

Abaixo da classificação e origem na barra esquerda há um sub assunto, Origem, conforme Figura abaixo.

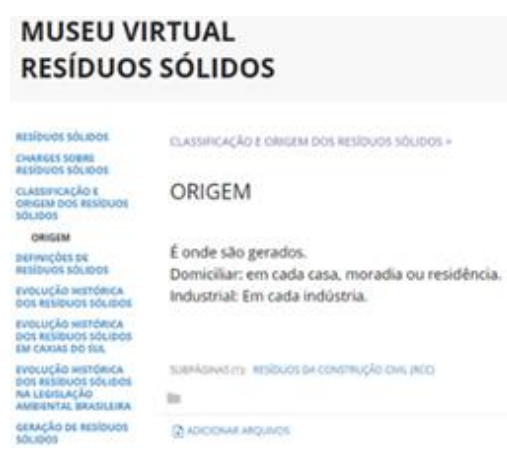

Figura 4: Página da Classificação e Origem. Fonte: elaborado pelo autor.

$\mathrm{Na}$ tela de Origem, ao final do texto explicativo, há como exemplo os Resíduos da Construção Civil (RCC).

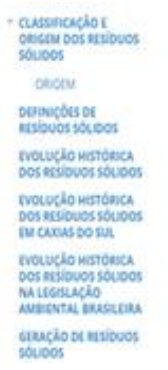

RESÍDUOS DA CONSTRUÇÃO CIVIL (RCC)

RESOLUCÃA NO 307, DE SDE JULHO DE 2002 Publicada no DOU n" 136 , de 171072002 Ant. $2^{\circ}$ Para efeito desta Resolujaso sdo adotadas as seguintes definiçes:

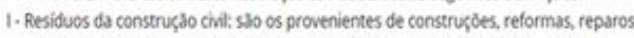

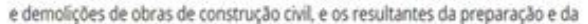
escavaç̧o de terrenos, tais como: tijolos, blocos cerdmicos, concreto em gerat, solos. rochas, metais, resinas, colas, tincas, mudeiras e compensodos, forros, argamassa,

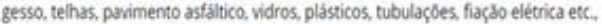
comumente chamados de entulhos de obras, calica ou metrahthr.

Figura 5: Página do RCC.

Fonte: elaborado pelo autor.

Os slides abaixo foram construídos para alimentar o site do MVRS. 
Quadro 1: Slides representativos dos tópicos do site MVRS.

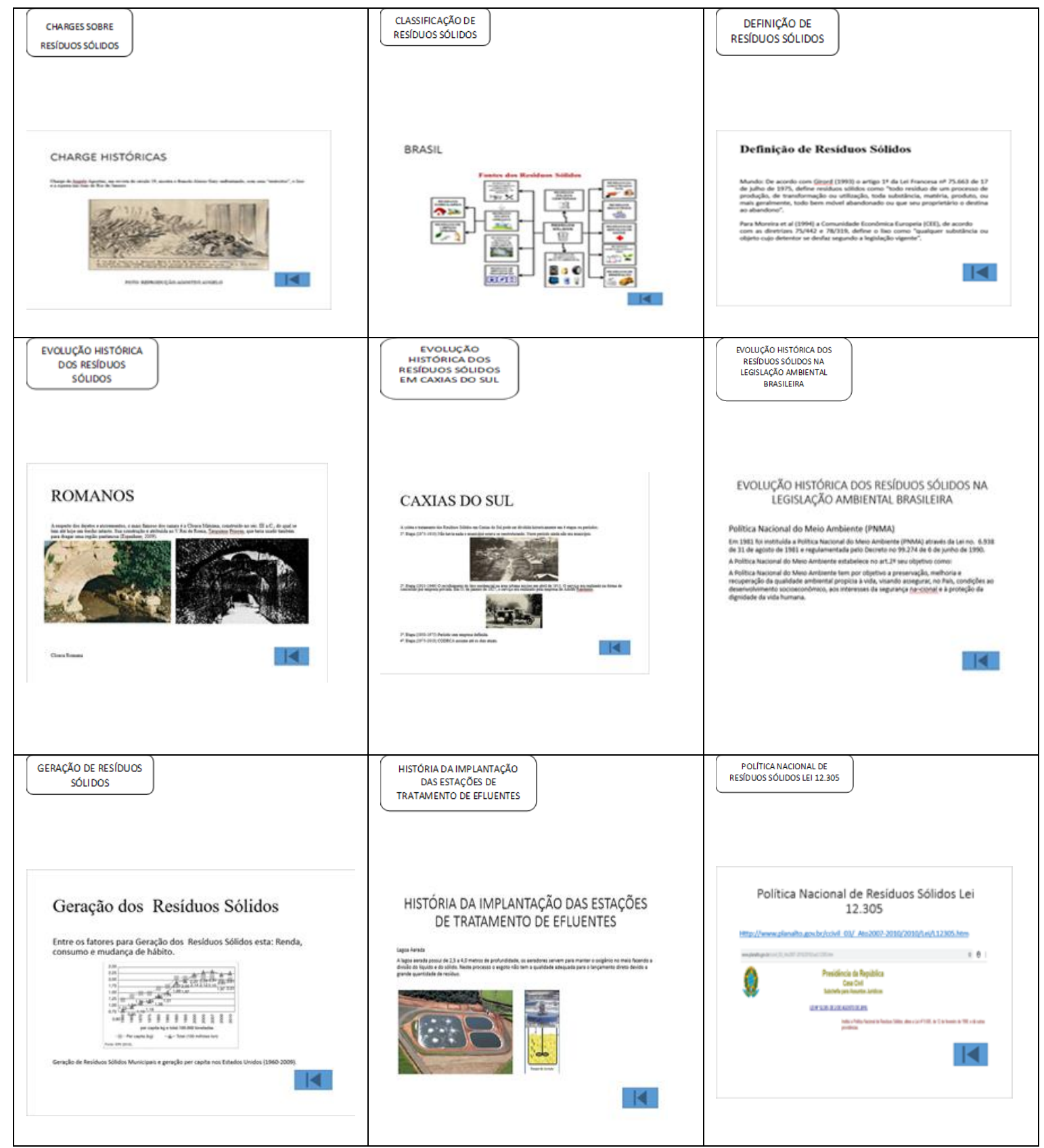

Continua...

Revbea, São Paulo, V. 14, № 3: 206-219, 2019.

revista brasileira educação ambiental 
...continuação.

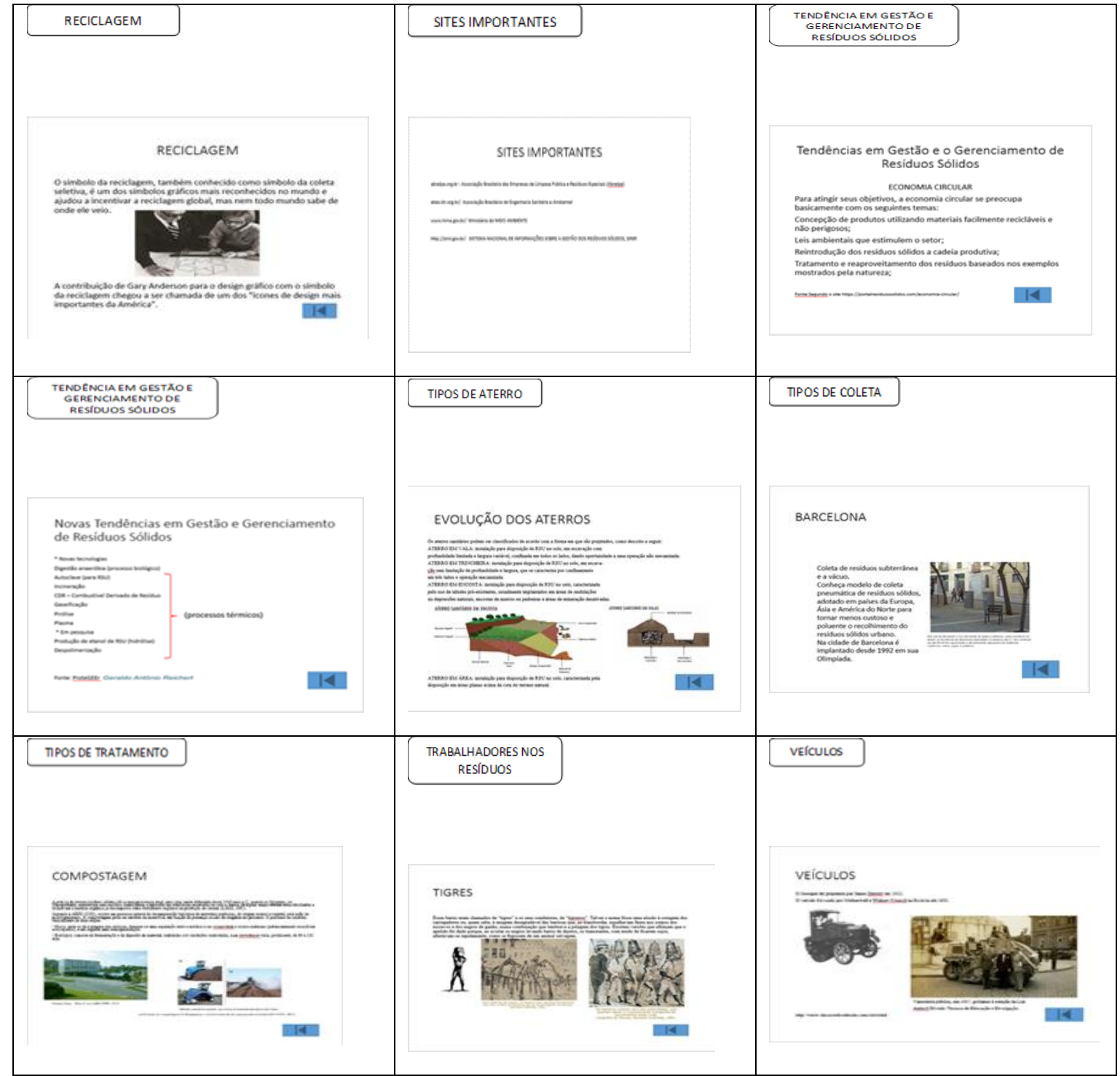

Fonte: elaborado pelo autor.

\section{Processo de Avaliação do MVRS}

Os resultados da avaliação do MVRS podem ser vistos nas Figuras de 6 a 9 e no Quadro 2.

A Figura 6 mostra a primeira impressão que os participantes da avaliação tiveram ao acessar o site do MVRS e a Figura 7 traz a percepção dos participantes sobre qual dos Resíduos causa mais impacto ao meio ambiente. 


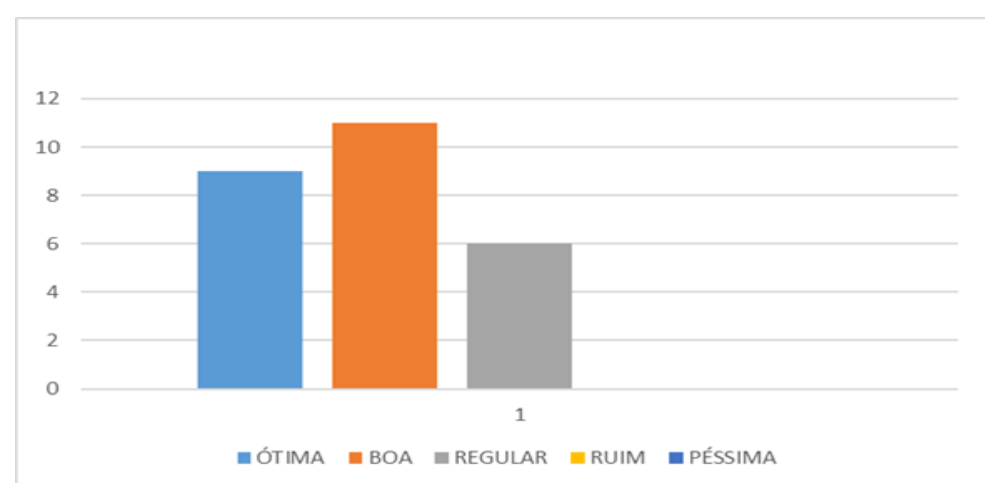

Figura 6: Distribuição das percepções dos avaliadores do site do MVRS.

Fonte: Elaborado pelo autor.

A primeira impressão que tiveram ao acessar o site foi ótima para 11 avaliadores, para nove (9) avaliadores foi boa e para seis (6) avaliadores regulares. Pelas respostas é possível perceber que a maior parte dos participantes consideram o MVRS bom ou ótimo. Mesmo assim, as avaliações como "regulares" apontam para necessidade de aprimoramento do site.

A Figura 7 mostra quais são os resíduos sólidos que causam mais impacto ao meio ambiente, segundo os participantes que avaliaram assim.

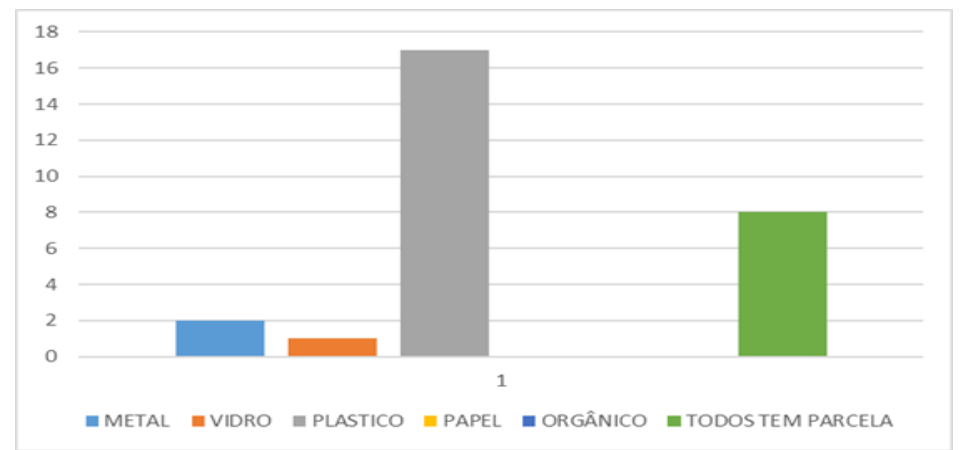

Figura 7: Distribuição dos Resíduos Sólidos que causam mais impacto ao meio ambiente, segundo os participantes. Fonte: Elaborado pelo autor.

Para 17 avaliadores o plástico é o que causa mais impacto ao meio ambiente, sendo que para oito (8) todos os resíduos sólidos produzem impacto negativo ao meio ambiente. Os efeitos negativos do plástico sobre o ambiente estão suficientemente mapeados no mundo, mesmo assim seu consumo tem aumentado. Esse conhecimento provavelmente influenciou a resposta dos avaliadores no sentido de apontar o plástico como o principal resíduo em termos de impactos negativos sobre o ambiente. Convém destacar, no entanto, que produtos químicos, resíduos de construção civil, resíduos industriais, pneus, entre outros tantos, causam prejuízos incontestáveis ao equilíbrio ambiental.

A Figura 8 mostra a frequência com que os avaliadores utilizam a 
internet ao dia e a avaliação do site quanto a disponibilidade da informação e quanto a ideia do site do MVRS.

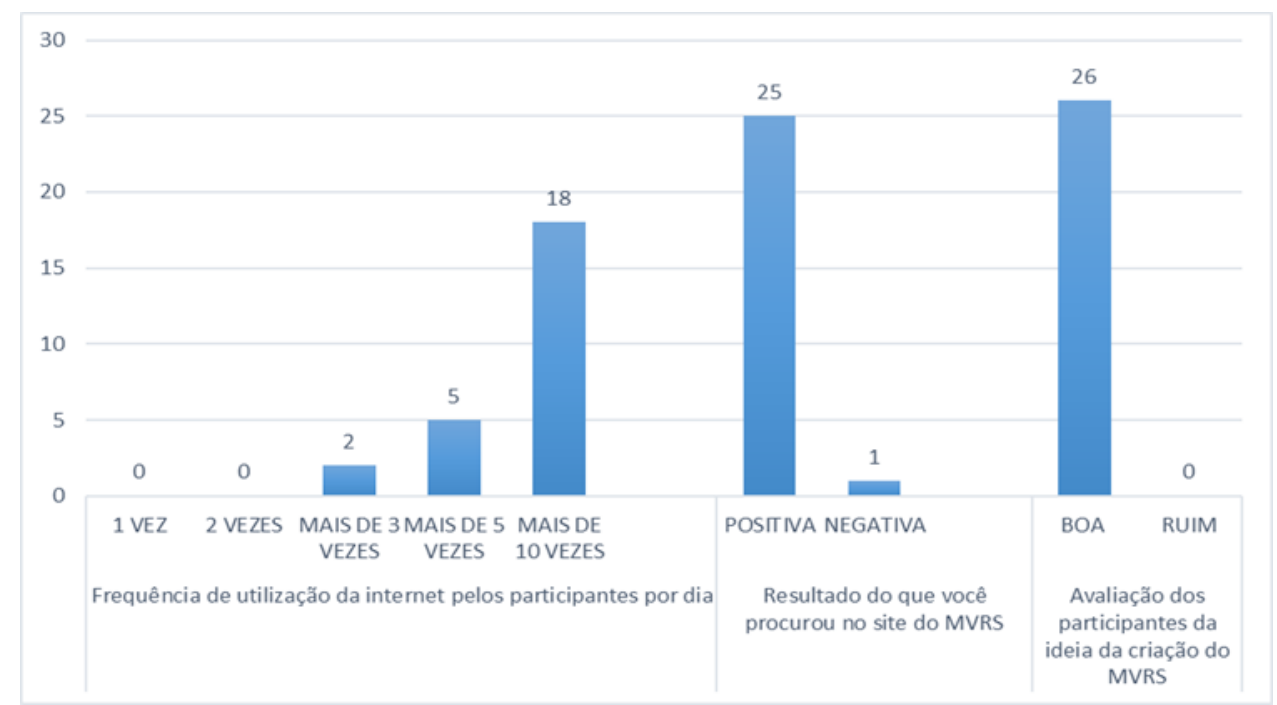

Figura 8: Distribuição da frequência de utilização da internet, da disponibilidade de informação do MVRS e da ideia da criação do MVRS. Fonte: Elaborado pelo autor.

Se observa que a maioria dos avaliadores utilizam a internet mais de 10 vezes ao dia, a grande maioria dos avaliadores (25) encontraram o que estavam procurando no site do MVRS e todos os avaliadores disseram que a criação do site do MVRS é uma boa ideia. Esses resultados, no conjunto, mostram que um museu virtual pode ser uma estratégia importante para socialização de conhecimentos sobre resíduos e sua forma de manejo ambientalmente correta.

A Figura 9 faz referência a navegabilidade do site MVRS, a facilidade de acesso a informação, a qualidade da informação e o uso das mesmas.

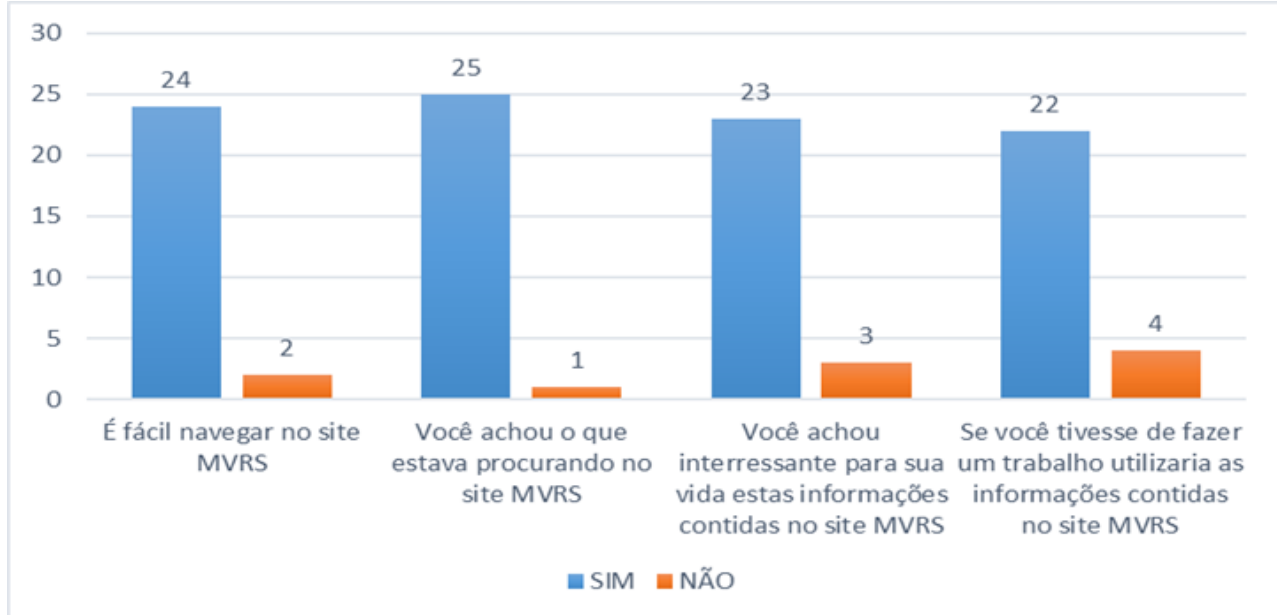

Figura 9: Distribuição da frequência quanto a navegabilidade, disponibilidade da informação e ideia de criação do MVRS. Fonte: Elaborado pelo autor.

Revbea, São Paulo, V. 14, № 3: 206-219, 2019. 
A grande maioria dos avaliadores disseram que é fácil navegar no site do MVRS, 25 dos avaliadores encontraram o que procuravam no site do MVRS, 23 avaliadores acharam interessantes para suas vidas as informações contidas no mesmo e 22 utilizariam as informações para realizarem seus trabalhos.

O Quadro 2 apresenta as sugestões dos avaliadores sobre o que poderia ser implementado ou retirado do site do MVRS.

Quadro 2: Sugestões dos avaliadores sobre o MVRS.

\begin{tabular}{|l|r|}
\hline Sugestões & No. \\
\hline Faltou imagens, fotos e videos acompanhando os tópicos para ficar mais atrativo & 5 \\
\hline Esta muito bom & 5 \\
\hline Colocar melhor as referências & 2 \\
\hline Acessibilidade: tamanho da fonte ( para baixa visão) e Internet para surdos & 2 \\
\hline Tornar mais atrativo visualmente o site ou Design mais atrativo & 2 \\
\hline Criar aba para gerenciamento de resíduos & 1 \\
\hline Colocar situaçães impactantes & 1 \\
\hline Faltou um tópico com perspectivas futuras de melhoria na área de Resíduos Sólidos & 1 \\
\hline Uma inter-relação mais completa, com um processo mais explicativo dos tópicos & 1 \\
\hline Melhorar a configuração do site & 1 \\
\hline Colocar links para outros museus & 1 \\
\hline Trazer mais artigos da atualidade & 1 \\
\hline Padronização de alguns termos técnicos Ex.: esgoto-efluente, lixo-resíduo & 1 \\
\hline Mostrar mais coisas atuais & 1
\end{tabular}

Fonte: Elaborado pelo autor.

Houveram sugestões variadas, destacando-se: a falta de imagens, fotos e vídeos acompanhando os tópicos para ficar mais atrativo (cinco avaliadores; incluir mais referências (dois avaliadores); acessibilidade (tamanho da fonte, para baixa visão) e Internet para surdos feita por outros dois (2) avaliadores; e padronização de alguns termos técnicos como esgoto - efluente, lixo - resíduo, sugerido por um (1) avaliador.

Cinco (5) avaliadores que consideraram o site do MVRS muito bom.

As sugestões apresentadas contribuirão para o aperfeiçoamento do site do MVRS e devem ser colhidas constantemente, quando o MVRS for disponibilizado ao público, como forma de manter permanente processo de aperfeiçoamento do conteúdo.

A avaliação feita pelos participantes demonstra que a construção do site do MVRS foi bem aceita pelo público que o avaliou e tem muito a crescer com as sugestões que foram dadas. 


\section{Conclusões}

Considerando a necessidade cada vez mais urgente de criar soluções ao problema dos resíduos, e que o acesso a informação de qualidade é um requisito importante a população em geral, um Museu Virtual de Resíduos mostra-se como importante ferramenta de socialização de conhecimentos. De forma semelhante ao que ocorre com Museus presenciais, um Museu Virtual exige uma busca ininterrupta de acervo para garantir "visitação" permanente.

Da mesma forma exige uma avaliação e monitoramento constante, a fim de aprimorar, tanto questões conceituais e emergentes, quanto incluir objetos de aprendizagem mais direcionados a determinadas parcelas da população, como por exemplo, a inclusão de jogos ou espaços interativos específicos a crianças em idade escolar.

A experiência de construção do Museu e sua avaliação inicial permite afirmar que ele tem potencial para constituir-se em uma ferramenta de Educação Ambiental para ser usado também no ensino informal ou não formal.

\section{Referências}

BRASIL. Resolução № 2, de 15 de junho de 2012. Estabelece as Diretrizes Curriculares Nacionais para a Educação Ambiental. Brasília, DP: Ministério da Educação, 2012. Disponível em: <http://conferenciainfanto.mec.gov.br/ images/conteudo/iv-cnijma/diretrizes.pdf>. Acesso em 24 de agosto de 2019.

BRASIL. LEI No 9.795, de 27 de Abril de 1999. Dispõe sobre a Educação Ambiental, institui a política nacional de Educação Ambiental e dá outras providências, 2019. Disponível em: <http://www.planalto.gov.br/ccivil 03/ leis/L9795.htm > Acesso em: 22 de ago. 2019.

BRASIL. LEI № 12.305, de 2 de agosto de 2010. Institui a Política Nacional de Resíduos Sólidos; altera a Lei no 9.605, de 12 de fevereiro de 1998; e dá outras providências. Disponível em: <http://www.planalto.gov.br/ccivil 03/ ato 2007-2010/2010/lei/l12305.htm> Acessado em: 12 de nov. 2018.

BRASIL. Lei no 11.904 Institui o Estatuto de Museus, 2009.

INTERNATIONAL COUNCIL OF MUSEUMS (ICOM). Statutes: approved in Vienna (Austria) August 24, 2007. Paris, 2007. Disponível em: $<$ http://icom.museum/statutes.htm|\#top>. Acesso em: 20 nov. 2018.

LÉVY, P. Cibercultura. São Paulo: Editora 34, 1999.

MENEZES, S.J. M.; DOMINGUES, G. F.; LIMA, C. A.; LANA, V. M.; RIBEIRO, C. A. A. S.; LIMA, C. A. (2012). Educação Ambiental: Utilização de geotecnologias na disseminação da percepção ambiental. Revista Brasileira de Educação Ambiental, v. 7, n. 1, p. 21-28. 
PEINADO, J.; GRAEML, A.R. Administração da produção: operações industriais e de serviços. Curitiba: UnicenP, 2007. Disponível em:<http://www.eumed.net/cursecon/ecolat/br/17/proposta-mudanca-layout. html.> Acesso em: $10 \mathrm{dez} .2018$

PELICIONI, M. C. F. (2015). Fundamentos da Educação Ambiental. In: PHILIPPI JÚNIOR, A.; ROMÉRO, M.A.; BRUNA, G.C. Curso de Gestão Ambiental. (2a, Cap. 13, pp. 469-491). Barueri, SP: Manole, 2015.

SOUZA, R. M. O papel das Redes de Informação e Conhecimento nas Tramas da Educação Ambiental. Revista Brasileira de Educação Ambiental, v..3, n.1, p. 105-111, 2008. 